\title{
Spatial heterogeneity in root litter and soil legacies differentially affect legume root traits
}

\author{
Sirgi Saar • Marina Semchenko • Janna M. Barel • \\ Gerlinde B. De Deyn (D)
}

Received: 1 October 2017 / Accepted: 21 February 2018 / Published online: 11 May 2018

(C) The Author(s) 2018

\begin{abstract}
Background and Aims Plants affect the soil environment via litter inputs and changes in biotic communities, which feed back to subsequent plant growth. Here we investigated the individual contributions of litter and biotic communities to soil feedback effects, and plant ability to respond to spatial heterogeneity in soil legacy. Methods We tested for localised and systemic responses of Trifolium repens to soil biotic and root litter legacy of seven grassland species by exposing half of a root system to control soil and the other half to specific inoculum or root litter.

Results Soil inoculation triggered a localised reduction in root length while litter locally increased root biomass independent of inoculum or litter species identity. Nodule formation was locally suppressed in response to soil conditioned by another legume (Vicia cracca) and
\end{abstract}

Responsible Editor: Alfonso Escudero.

Electronic supplementary material The online version of this article (https://doi.org/10.1007/s11104-018-3667-9) contains supplementary material, which is available to authorized users.

S. Saar · J. M. Barel • G. B. De Deyn $(\bowtie)$

Department of Soil Quality, Wageningen University, P.O. Box 47, 6700 AAWageningen, The Netherlands

e-mail: gerlinde.dedeyn@wur.nl

S. Saar

Department of Botany, Institute of Ecology and Earth Sciences, University of Tartu, 40 Lai St, 51005 Tartu, Estonia

M. Semchenko

School of Earth and Environmental Sciences, University of Manchester, M13 9PT, Manchester, UK showed a trend towards systemic reduction in response to conspecific soil. V. cracca litter also caused a systemic response with thinner roots produced in the part of the root system not directly exposed to the litter.

Conclusions Spatial heterogeneity in root litter distribution and soil communities generate distinct local and systemic responses in root morphology and nodulation. These responses can influence plant-mutualist interactions and nutrient cycling, and should be included in plant co-existence models.

Keywords Functional traits - Local and systemic response $\cdot$ Plant-soil feedback $\cdot$ Root litter $\cdot$ Soil heterogeneity $\cdot$ Spatial root distribution

\section{Introduction}

Due to their sessile lifestyle but variable environment, plants have evolved remarkable plasticity in their growth and morphology above and below ground (Fitter 1994; de Kroon and Hutchings 1995; Palmer et al. 2012). Below ground, plants experience spatial heterogeneity in nutrient supply, in density and identity of roots (alive and dead) of different species and their associated microbial communities. Many plant species are known to place their roots and prolong their residency preferentially in patches with high nutrient content (Hodge 2004; Bradford et al. 2007). Evidence is also accumulating for plasticity in root distribution and morphology to the presence and identity of living neighbouring roots (Cahill et al. 2010; Semchenko 
et al. 2014). However, how plants respond to spatial heterogeneity in soil legacies left behind by deceased predecessors is still poorly understood.

Plants interact with soil biota and drive specific changes in soil microbial community composition and soil functioning (Grayston et al. 1998; Garbeva et al. 2004; Schlatter et al. 2015). These changes in the microbial communities can persist in the soil after plant death and together with the decomposing roots affect subsequent plant growth via so-called plant-soil feedback (PSF) effects (Ehrenfeld et al. 2005; Hendriks et al. 2013; Mack and Bever 2014; Zhang et al. 2016). Comparative studies examining the individual effects of root litter and soil microbial legacies on succeeding plants are currently lacking, which hinders mechanistic understanding of the factors determining the outcome of plant-soil interactions (van der Putten et al. 2013). Moreover, while feedback effects on overall plant growth and survival have been extensively studied (Bever 2003), the ability of plants to modify their morphology in response to soil legacies is still poorly understood (Baxendale et al. 2014), particularly under heterogeneous soil conditions (Hendriks et al. 2015a; Wubs and Bezemer 2016).

Soil feedback effects on succeeding plants could act via litter decomposition and mineralisation and the associated changes in plant-available nutrients (Hobbie 2015). The ability of plants to forage for heterogeneously distributed nutrients and the implications of foraging precision have been extensively studied. Preferential root placement in patches with high nutrient concentrations is often achieved by changes in root biomass distribution, but also by producing more branched and thinner roots (Hutchings and John 2003; Hodge 2004; Cahill and McNickle 2011). In addition to local conditions, root proliferation in soil patches is controlled systemically by nutrient status of the whole plant (Zhang et al. 1999; Lamb et al. 2004). If root litter primarily affects plants through increased nutrient availability due to mineralisation, then responses similar to those observed for nutrient heterogeneity are expected to occur in response to litter heterogeneity. Therefore, it can be predicted that $\mathrm{N}$-rich litter of legumes induces a stronger local foraging response than the more recalcitrant litter produced by slow-growing grass species.

In addition to the effects mediated by litter decomposition, soil microbial legacies involve plant pathogens and symbionts and may induce both localised and systemic responses in root systems. Due to the host specificity of both pathogenic and symbiotic plantmicrobe interactions, the strongest responses are expected to occur in reaction to soil patches previously occupied by conspecifics or closely related plant species (Bever 1994; Kulmatiski et al. 2008; van de Voorde et al. 2011). Local responses of plant roots may be efficient in case of organ-specific pathogens with limited mobility, while induced systemic response is expected to be favoured in case of attack by a pathogen that is likely to spread and infect other parts of the plant (He et al. 2002; Balmer et al. 2013). Besides physiological responses, plants may increase both local and systemic investment in structural defences (Yedidia et al. 1999), leading to changes in root diameter and specific root length (Eissenstat 1992; Eissenstat and Yanai 1997). A systemic response could also be manifested in compensatory root proliferation in soil patches uninfected by pathogens in response to a localised pathogen attack elsewhere in the root system (Steinger and MüllerSchärer 1992; Hendriks et al. 2015b).

Soil microbial legacies can also affect association between plants and microbial symbionts such as nitrogen-fixing bacteria (Liu et al. 2016). The association with nitrogen-fixing bacteria within root nodules is systemically regulated by aboveground plant organs, as they maintain the balance between energetic costs and nitrogen demand (Sasaki et al. 2014). Inefficient local nodulation can also induce other parts of the root system to compensate for the perceived $\mathrm{N}$ limitation by increased nodulation (Laguerre et al. 2012). To date, it remains to be tested to which extent root nodule formation in legumes is responsive to litter and soil legacies of plants, and whether such responses are local or also systemic. Root litter and soils conditioned by nonlegumes may reduce the abundance of nitrogen-fixing bacteria and induce local avoidance responses and/or systemic compensatory responses in the root systems of legumes, relative to soils conditioned by legumes. It has also been shown that interactions between legumes and Rhizobium are highly species-specific (Wang et al. 2012; Keller 2014). Therefore, variation in nodulation efficiency could also be expected in response to soil conditioned by different legume species.

While many studies have investigated microbially mediated plant-soil feedback (PSF), the relative contribution of soil microbial community versus root litter legacy to plant growth and belowground foraging is poorly understood, yet important in order to make PSF effects more predictable (van der Putten et al. 2013; 
Cortois et al. 2016). The aim of this study was therefore to investigate whether soil biota and root litter induce distinct responses in a focal legume plant at local and whole root system level, and to test if variation in these responses depends on soil inoculum and root litter identity. Specifically, the following hypotheses were tested: 1) focal legume plants exhibit localized and systemic responses in their root traits when exposed to root litter or soil inoculum from different plant species; 2) these responses vary depending on the species identity and functional group (legumes vs non-legumes) of plants that produced the litter or conditioned the soil; 3) litter nutrient content explains variation in the legume responses to root litter produced by different species.

To test these hypotheses, we conducted a split-pot experiment with Trifolium repens (L.) as the focal species. T. repens was chosen due to the importance of $\mathrm{N}$ fixation in grassland ecosystems as well as the wide use of legumes as green manure and cover crops. Moreover, legumes form specialist mutualisms with $\mathrm{N}$-fixing bacteria (Dassen et al. 2017) making them highly suitable for studying plant-soil feedbacks. In the split-pot experiment, $T$. repens roots were subjected to either root litter or inoculum from soils previously occupied by conspecifics or a range of other species in one compartment, and non-specific background soil without root litter in the other compartment. As a control, we grew T. repens in split-pots where both compartments contained nonspecific background soil. This approach allowed the identification of local responses, i.e. changes in root traits appearing only in the compartment that received litter or soil inoculum, and systemic effects that also encompassed root responses in the compartment where the roots had no direct contact with litter or specific soil microbes. We predicted that $T$. repens would proliferate its roots in patches with presence of root litter of high $\mathrm{N}$ content and that its roots would avoid patches with microbial legacies of its own species as most conspecific soil feedbacks are negative (Kulmatiski et al. 2008; Hendriks et al. 2015a, b; Cortois et al. 2016).

\section{MATERIALS AND METHODS}

Conditioning phase

Soil for all treatments was collected from a semi-natural grassland site in Netherlands in spring 2013 ('Clue' site, Mosselse Veld, $\left.52^{\circ} 04^{\prime} \mathrm{N}, 5^{\circ} 45^{\prime} \mathrm{E}\right)$. The soil is sandy- loam, with particle size distribution: $<2 \mathrm{~mm}, 3.4 \%$; $2-$ $63 \mathrm{~mm}, 17.3 \%$; > $63 \mathrm{~mm}, 79.7 \%, \mathrm{pH} \mathrm{H}_{2} \mathrm{O} 6.4$ and \%OM 4.5 (Van der Putten et al. 2000; Bezemer et al. 2010). The soil was sieved $(8 \mathrm{~mm})$ and stored at $4{ }^{\circ} \mathrm{C}$. Pots with a volume of 21 were filled with a soil mixture consisting of $85 \%$ sterilised soil (25 kGray) and $15 \%$ fresh soil to reintroduce the natural soil microbial community. The bulk of the soil was sterilised to eliminate weeds and insect herbivores. Reinoculation of sterilised soil with living soil inoculum ensured the soil microbial community adaptation to the conditioning plant species (Francioli et al. 2016). The soil was subsequently conditioned by each of seven species naturally occurring in temperate semi-natural grasslands on sandy soil: 3 grasses (Lolium perenne, Festuca rubra and Arrhenatherum elatius), 3 legumes (Trifolium repens, Trifolium pratense and Vicia cracca) and a forb (Cichorium intybus). The seeds were purchased from specialised companies: T. pratense and C. intybus from Cruydt-Hoeck (Groningen, Netherlands), L. perenne and T. repens from Agrifirm (Apeldoorn, Netherlands), V. cracca, F. rubra and A. elatius from Emorsgate (Norfolk, UK). Before planting, the seeds were surface sterilised with $10 \%$ household bleach solution for $30 \mathrm{~s}$, rinsed repeatedly with tap water and germinated on autoclaved sand. Two weeks after germination, eight seedlings of each species were planted as a single individual per pot and were grown in a greenhouse for 12 weeks with additional illumination to achieve $16 \mathrm{~h}$ of daylight and with a day:night temperature cycle of $21: 16^{\circ} \mathrm{C}$ to create eight independent replicates of conditioned soil per plant species. At harvest, shoots were separated from roots, and the roots were removed from the soil and washed before drying at $40^{\circ} \mathrm{C}$ for a week to be used as root litter in the feedback experiment. The conditioned soil was kept separate per pot, sieved $(5 \mathrm{~mm})$ and preserved in dark at $4{ }^{\circ} \mathrm{C}$ temperature until its use in the feedback experiment.

Feedback phase

Trifolium repens L. was used as focal response plant. The feedback phase of the experiment was conducted in the greenhouse during January to May 2014. Seeds of T. repens were sterilised for $1 \mathrm{~min}$ in $10 \%$ household bleach solution, rinsed with tap water and sown in $200 \mathrm{ml}$ plastic cups in a soil mixture consisting of $90 \%$ sterilised and $10 \%$ non-sterilised field soil $(85.8 \pm 5.0 \mathrm{P}-$ $\mathrm{PO}_{4}, 270.6 \pm 15.0 \mathrm{~N}-\mathrm{NH}_{4}, 91.4 \pm 15.0 \mathrm{~N}-\left(\mathrm{NO}_{3}+\mathrm{NO}_{2}\right)$ 
mg per kg soil dry weight). After eight weeks the plants were prepared for transplanting, their roots rinsed with tap water and the main root of each plant clipped to $2 \mathrm{~cm}$ length. The $T$. repens plants were then transplanted into split-pots such that the roots were distributed equally between the two compartments of the split-pot. Splitpots were constructed by gluing together two $11 \times 11 \times 12 \mathrm{~cm}$ plastic pots creating one experimental unit with two compartments (Supplementary material, Fig. S1). A shallow wedge was cut in the partitioning wall so that each plant could be placed on the top of the partitioning wall of the two compartments. The soil surface was covered with a thin layer of autoclaved sand to prevent moss and algal growth.

Plants were subjected to two treatments: a soil microbial legacy and a litter legacy treatment. We did not combine the microbial and litter legacy treatments in a factorial design as each treatment was represented by seven levels, so that a full-factorial design would result in a vast number of combinations, measurements and comparisons. Instead, this experiment treated microbial and litter legacies separately with the aim of assessing their individual effects on plant foraging. For the soil microbial legacy treatment one of the compartments was filled with an unconditioned soil mixture consisting of $10 \%$ unconditioned field inoculum and $90 \%$ sterilised soil (same mixture as for seedling rearing) and the other compartment inoculated with soil conditioned with one of the seven plant species (10\% conditioned soil mixed with $90 \%$ sterilised soil). The control treatment received the unconditioned soil mixture in both compartments. For each treatment with soil of different plant species, four independent soil pools conditioned by each plant species were prepared by pooling soils from two out of eight pots of same species from the conditioning phase. This was done to match the litter legacy treatment where litter was pooled in the same combinations to ensure sufficient litter quantity.

For the root litter legacy treatment, both compartments were filled with the unconditioned soil mixture (10\% unconditioned field soil and $90 \%$ sterilised soil) and with one of the compartments containing a litterbag with root litter of one of the seven plant species. In the control treatment, an empty litterbag was inserted in one of the compartments. The root litter was composed of fine roots (diameter $<2 \mathrm{~mm}$ ), dried at $40{ }^{\circ} \mathrm{C}$ and cut to $5 \mathrm{~mm}$ long pieces. Each litterbag contained $0.5 \mathrm{~g}$ of dried root litter, which was obtained by pooling roots of two conspecific individuals to obtain enough root litter for filling two litterbags. This resulted in four independent root litter pools per root litter species, each containing roots of two individuals of the same plant species. The same combinations of pots were used for pooling root litter as those used for pooling the soil inocula. The litterbags were made of polyester fabric (mesh size $<0.05 \mathrm{~mm}$, litter bag size $70 \times 70 \mathrm{~mm}$ ). Litterbags were placed vertically with outer edge at a distance of $2 \mathrm{~cm}$ from the pot border and upper edge slightly covered with sand (Supplementary material, Fig. S1).

There were eight replicates per treatment per species resulting in a total of 64 pots for the soil inoculum treatment and 64 pots for the root litter treatment. Each root litter and soil inoculum pool of each conditioning species was represented by two pots. The pots were placed in a greenhouse in a randomised block design with eight blocks. Three weeks after planting, leaves and protruding stems were clipped to $2 \mathrm{~cm}$ height to prevent clonal spread into neighbouring pots and stimulate root growth. The plants were kept in a greenhouse at $16: 21{ }^{\circ} \mathrm{C}$ night:day cycle with additional lighting to achieve $16 \mathrm{~h}$ day length from beginning to the end of experiment during 16 weeks. The pots were watered daily to $60 \%$ water holding capacity by adjusting the weight loss of the pot due to evapotranspiration.

\section{Measurements}

We determined the concentrations of $\mathrm{N}, \mathrm{P}$ and $\mathrm{C}$ on a subsample of each root litter pool before the start of the feedback experiment as described in Saar et al. (2016). The subsamples of dried roots were ground, then mineralised using $\mathrm{H}_{2} \mathrm{SO}_{4} / \mathrm{H}_{2} \mathrm{O}_{2} / \mathrm{Se}$ wet digestion (Novozamsky et al. 1983), and subsequently analysed for total $\mathrm{N}$ and $\mathrm{P}$ content using Segmented Flow Analyses (SFA). Another subsample of ground roots was used to quantify the $\mathrm{C}$ and $\mathrm{N}$ concentration in the litter using a CN elemental analyser (LECO, Germany). Due to limited litter availability for this $\mathrm{CN}$ analysis, there were 3 instead of four replicates for $L$. perenne, T. pratense and V. cracca and two for T. repens.

Plants were harvested eight weeks after planting. Aboveground biomass was removed and roots washed out separately from the two compartments. A representative root sample was preserved in 50\% alcohol from each compartment which was used for scanning and quantification of specific root length (SRL; scanned root length/ scanned root dry mass), average root diameter, root branching frequency (the number of root tips per unit of 
scanned root length) and the number of nodules per gram of dry root mass using WinRhizo Pro 2013e to analyse the scanned images. Shoots, scanned and remaining roots were dried at $40{ }^{\circ} \mathrm{C}$ for $48 \mathrm{~h}$ and weighed separately.

\section{Statistical analysis}

Data analyses were performed using $\mathrm{R}$ (version 3.1.2). All response variables were $\ln$-transformed prior to analysis to satisfy model assumptions. The effects of litter addition and soil inoculum from different species on the traits of the response plant $T$. repens were tested separately using linear mixed models (package lme4 (Bates et al. 2014)) with litter or soil origin (seven conditioning species), compartment (treatment or untreated) and their interaction as fixed factors, pot nested within block as random factors, and root biomass, root diameter, SRL, branching frequency and the number of nodules per gram of root dry mass of $T$. repens as response variables. The same model but without the factor compartment was used to analyse data on total shoot biomass. The inclusion of litter and soil inoculum pool as additional random factors did not significantly improve model fit and produced nearly identical estimates for fixed effects; these random factors were hence excluded from the final analyses. Local response is signified by a change in root traits in the treated compartment (with a specific soil inoculum or root litter), while significant changes in both compartments or in the untreated compartment only (not directly exposed to a specific soil inoculum or root litter) signifies a systemic response.

To test the effects of plant functional group on root traits (Hypothesis 2), linear mixed models were used with functional group (legume or non-legume) and compartment as fixed factors, and pot nested within block and soil or litter species as random factors. To test the role of litter properties (Hypothesis 3), we calculated response ratios as $\ln$ (treated compartment/control compartment), averaged response ratios by litter pool (there were four litter pools per species distributed among 8 pots, therefore averaging across 2 pots) and used linear models with the mean response ratio as a response variable, litter N, P or CN as fixed factors and root litter species as a random factor.

To test if localised plant responses to litter deviated significantly from the control treatment with an empty litter bag, response ratios were calculated as $\ln$ (treated compartment/untreated compartment) and linear mixed models were used with litter origin (seven species plus the control) as a fixed factor and block as a random factor. Species-specific response ratios were compared to the empty-litterbag control treatment as a reference level using t-tests. To test for the significance of overall localised responses (main effect of compartment in the models described above) compared to the control treatment with an empty litterbag, Helmert contrasts and t-test were used to compare the response ratios of all seven conditioning species combined to the response ratio of the control treatment. To test for the significance of a localized response to soil conditioning, the mean trait value in the compartment with inoculum was compared to the mean trait value in the control treatment with unconditioned soil in both compartments using t-tests as described above. To test if systemic plant responses deviated significantly from the control treatments (empty litterbag or unconditioned soil in both compartments), linear mixed models were used with soil or litter origin (seven species plus the control) as a fixed factor and pot nested within block as random factors and ln-transformed trait as a response variable. Helmert contrasts and t-test were used to compare the mean trait value of all seven conditioning species combined to the mean of the control treatment. All Helmert contasts and t-tests were performed using lmer models and summary function in package lme 4 (Bates et al. 2014).

\section{RESULTS}

Plant responses to soil legacies

\section{Plant biomass}

Total aboveground biomass of $T$. repens was not affected by soil inoculum from the different plant species $\left(\mathrm{F}_{6,42}=0.82, P=0.5599\right)$ and similarly total root biomass of $T$. repens was not affected by soil inoculum (Fig. 1A; Table 1). Also when compared to the control the mean above- and belowground biomass across all soil inoculum treatments did not significantly differ from that of plants grown in unconditioned soil $(P>0.05$, t-test comparing the mean of conditioning treatments to the mean of the control).

\section{Root architecture and nodulation}

In contrast to plant biomass, T. repens showed local belowground responses to the soil microbial legacy from 
Fig. 1 The general effect of soil inoculum (A-B) and root litter addition (C-D) on root dry mass and total root length of Trifolium repens. The plants were grown in split-pots with one compartment treated (dark grey) with plant species specific soil inoculum (AB) or root litter (C-D), and the other compartment incoculated with unconditioned soil (untreated compartment; light grey). In the soil inoculum graphs (A-B) the solid line indicates the mean trait value for the control treatment with both compartments filled with unconditioned soil mixture. In the root litter graphs (C-D) the dashed and solid lines indicate mean trait values for the control treatment with one compartment filled with unconditioned soil only and the other compartment containing unconditioned soil and an empty litterbag, respectively. Asterisks indicate significant differences between untreated and treated compartments $(P<0.05$, Tukey test)

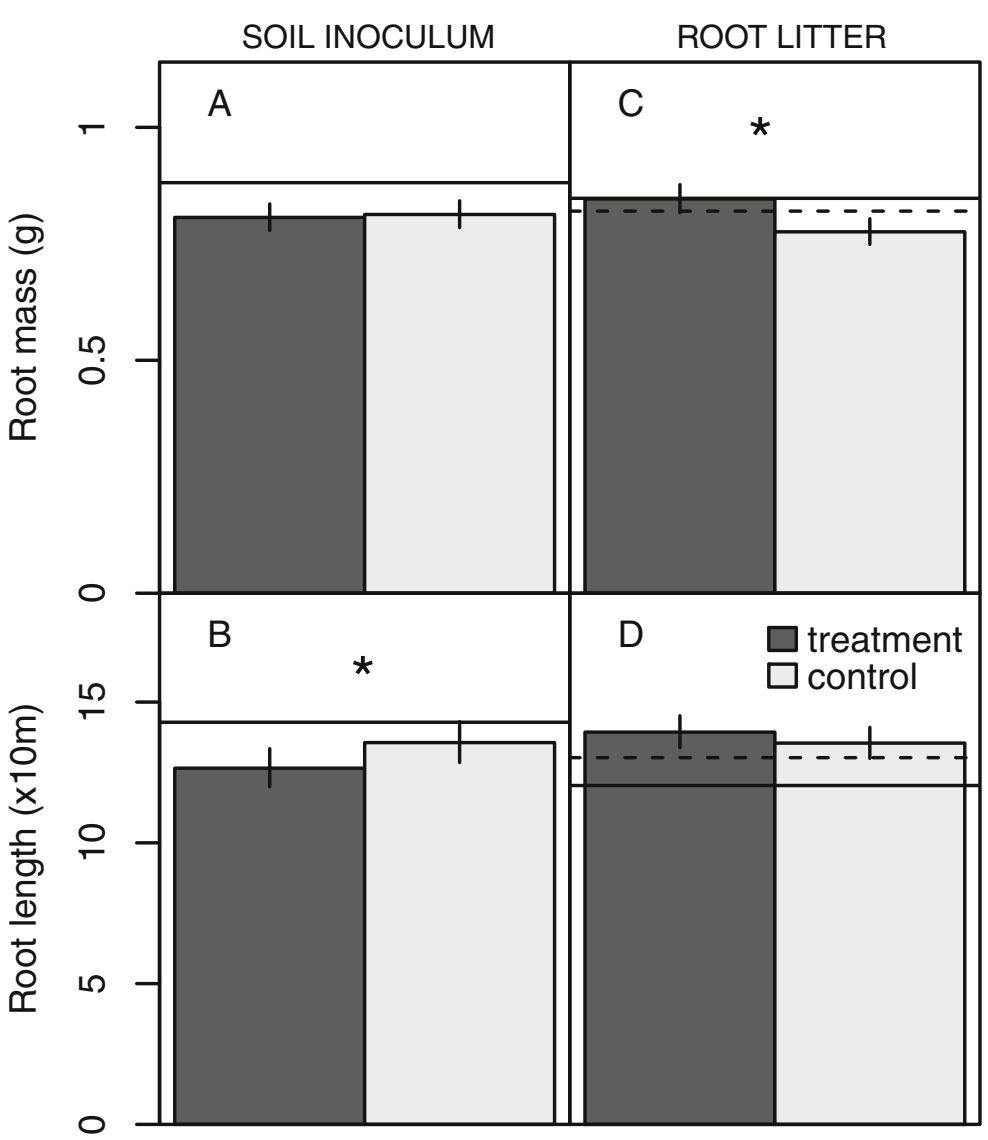

other plants, as indicated by the altered root architecture traits (Table 1, Figs. 1, and 2). Total root length displayed a significant local response to soil conditioning independent of species identity, as evidenced by less root length in the treated compartment compared to the untreated compartment (Table 1; Fig. 1B). The root length in the compartments treated with conditioned soil was however not significantly different from the control treatment with unconditioned soil in both compartments $(P=0.2305$, ttest). A specific soil conditioning effect was observed on

Table 1 Root trait responses of $T$. repens to soil inocula conditioned by seven plant species. Linear mixed models contained soil inoculum origin (seven species), compartment (inoculated vs. unconditioned) and their interaction as fixed factor and pot nested local nodulation (Table 1). Nodulation was strongly suppressed (by 71\%) in the compartment containing soil conditioned by Vicia cracca when compared with nodulation of roots in the untreated compartment (Fig. 2A). The production of root nodules in the $V$. cracca soil was also significantly lower compared to the unconditioned control treatment $(P=0.0298$, t-test $)$. No significant localised responses in nodule numbers were observed in response to other conditioned soils (significant interaction between soil legacy and compartment in Table 1). The

within block as random factors. F-values and their significance are shown. Values in bold indicate significant effects $(P<0.05)$ and marginally non-significant effects are shown in italic $(P<0.1)$; * indicates $P<0.05$; ** indicates $P<0.01$

\begin{tabular}{|c|c|c|c|c|c|c|c|}
\hline Factor & df & $\begin{array}{l}\text { Root mass } \\
(\mathrm{g})\end{array}$ & $\begin{array}{l}\text { Root length } \\
(\mathrm{cm})\end{array}$ & $\begin{array}{l}\text { Specific root length } \\
(\mathrm{cm} / \mathrm{mg})\end{array}$ & $\begin{array}{l}\text { Root diameter } \\
(\mathrm{mm})\end{array}$ & $\begin{array}{l}\text { Branching frequency } \\
\text { (tips } / \mathrm{m})\end{array}$ & $\begin{array}{l}\text { No. nodules/g root } \\
\text { mass }\end{array}$ \\
\hline Soil origin (S) & 6,42 & 1.35 & 0.85 & 1.04 & 0.61 & 1.00 & $4.29 * *$ \\
\hline $\begin{array}{l}\text { Compartment } \\
\text { (C) }\end{array}$ & 1,49 & 0.07 & $4.39 *$ & 3.56 & 0.90 & 1.65 & 1.03 \\
\hline $\mathrm{S} \times \mathrm{C}$ & 6,49 & 0.48 & 1.81 & 0.85 & 0.60 & 2.08 & $2.38 *$ \\
\hline
\end{tabular}


local response in nodule number tended to differ between functional groups: nodulation in legume soil was lower than in soil conditioned by non-legumes, but this effect was only marginally significant and probably due to the strong response to $V$. cracca soil inoculum (interaction between functional group and compartment, $\mathrm{F}_{1,54}=3.77$, $P=0.0574$ ). No significant systemic responses to soil inoculation were found for any of the measured plant traits (no significant effect of soil origin in Table 1), except for the trend towards lower nodulation in both treated and untreated compartments when $T$. repens plants were exposed to soil conditioned by conspecifics $(P=0.1150$, $\mathrm{t}$-test, $40 \%$ lower nodulation in plants exposed to soil conditioned by conspecifics compared to plants in the control treatment with unconditioned soil in both compartments).
Plant responses to root litter

\section{Plant biomass}

The local presence of root litter of the various plant species did not affect the total above- and belowground biomass of T. repens $\left(\mathrm{F}_{6,42}=0.28, P=0.9428\right.$ and main effect of litter origin on root mass in Table 2 , respectively). The mean above- and belowground biomass across all root litter treatments did not significantly deviate from that recorded for the control treatment with empty litterbags ( $P>0.05$, t-test). In contrast, root litter presence did affect the spatial distribution of the root biomass (significant main compartment effect in Table 2, Fig. 2C). T. repens had more root biomass in the treated compartment with litter compared to the untreated compartment, irrespective of the root litter species.

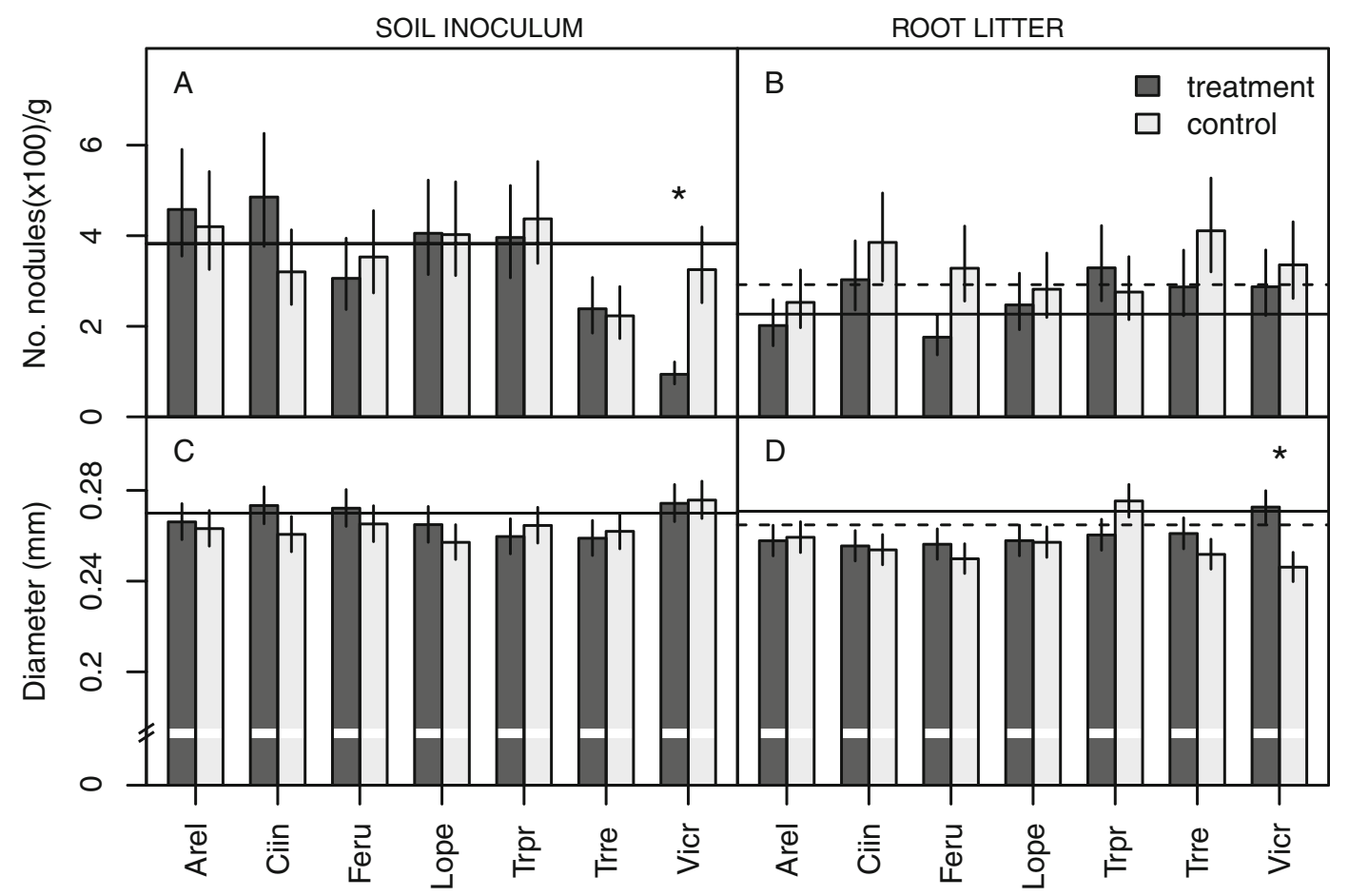

Fig. 2 The specific effect of soil inoculum (A-B) and root litter addition (C-D) originating from different plant species on the number of nodules produced per gram of dry root mass and root diameter of Trifolium repens. The plants were grown in split-pots with one compartment treated (dark grey) with specific soil inoculum (A-B) or specific root litter (C-D) and the other compartment inoculated with unconditioned soil with no litter addition (untreated compartment, light grey). In the soil inoculum graphs (A-B), the solid line indicates the mean trait value for the control treatment with both compartments filled with unconditioned soil mixture. In the root litter graphs (C-D), dashed and solid lines indicate mean trait values for the control treatment with one compartment filled with unconditioned soil only and the other compartment containing unconditioned soil and an empty litterbag, respectively. Conspecific treatments (Trre) are indicated in bold. Asterisks indicate significant differences between untreated (light grey) and treated (dark grey) compartments $(P<0.05$, Tukey test). Specific soil inoculum and root litter from: Arel - Arrhenatherum elatius, Ciin - Cichorium intybus, Feru - Festuca rubra, Lope Lolium perenne, Trpr - Trifolium pratense, Trre - Trifolium repens, Vicr - Vicia cracca 
Table 2 Root trait responses of T. repens to root litter from seven plant species. Linear mixed models contained soil inoculum origin (seven species), compartment (with $v s$. without litterbag) and their interaction as fixed factor and pot nested within block as random factors. F-values and their significance are shown. Values in bold indicate significant effects $(P<0.05)$ and marginally nonsignificant effects are shown in italic $(P<0.1)$; * indicates $P<0.05 ; * *$ indicates $P<0.01$

\begin{tabular}{llllllll}
\hline Factor & df & $\begin{array}{l}\text { Root mass } \\
(\mathrm{g})\end{array}$ & $\begin{array}{l}\text { Root length } \\
(\mathrm{cm})\end{array}$ & $\begin{array}{l}\text { Specific root length } \\
(\mathrm{cm} / \mathrm{mg})\end{array}$ & $\begin{array}{l}\text { Root diameter } \\
(\mathrm{mm})\end{array}$ & $\begin{array}{l}\text { Branching frequency } \\
(\mathrm{tips} / \mathrm{m})\end{array}$ & $\begin{array}{l}\text { No. nodules/ g root } \\
\text { mass }\end{array}$ \\
\hline $\begin{array}{c}\text { Litter origin } \\
(\mathrm{L})\end{array}$ & 6,42 & 0.71 & 0.80 & 0.29 & 0.67 & 1.04 \\
$\begin{array}{c}\text { Compartment } \\
(\mathrm{C})\end{array}$ & 1,49 & $\mathbf{8 . 6 1 * *}$ & 0.35 & 2.94 & 2.36 & $<0.01$ & $\mathbf{9 . 6 4 * *}$ \\
\begin{tabular}{l}
$\mathrm{L} \times \mathrm{C}$ \\
\hline
\end{tabular} & 6,49 & 0.35 & 0.45 & 1.20 & $\mathbf{3 . 0 8 *}$ & 1.10 & 0.85 \\
\hline
\end{tabular}

However, this local root biomass response was not significantly different from the empty litterbag control treatment ( $P=0.5318$, t-test comparing response ratios).

\section{Root architecture and nodulation}

There was a significant local response in nodule numbers to litterbag presence, irrespective of the identity of the root litter (significant main compartment effect in Table 2). Fewer nodules were produced in most treated compartments (Fig. 2B). However, this response was not significantly different from that observed in the control treatment with an empty litterbag $(P=0.9748$, t-test comparing response ratios of the pot half with and without litterbag). Root diameter also showed a significant response to litter presence and this effect was dependent on root litter identity (significant interaction between litter species and compartment in Table 2). Average root diameter was significantly reduced in the untreated compartment compared to the treated compartment with V. cracca litter (Fig. 2D), and differed significantly from the empty-litterbag control ( $P=0.0399$, t-test comparing response ratios). Variation in root diameter responses to the different root litter species could not be explained by the functional group (non-significant interaction between the effects of functional group and compartment, $\mathrm{F}_{1,54}=0.75, P=$ 0.3905). The root diameter response was also not significantly related to litter $\mathrm{N}\left(\mathrm{F}_{1,5}=0.5932, P=0.474\right)$ or $\mathrm{C}$ content $\left(\mathrm{F}_{1,20}=0.4009, P=0.5335\right)$ or to litter $\mathrm{C}: \mathrm{N}$ ratio (diameter $\mathrm{F}_{1,5}=0.0067, P=0.9378$ ).

\section{DISCUSSION}

The results of this study demonstrate that spatial heterogeneity in root litter distribution and soil microbial legacy can trigger localised and systemic response in the root systems of T. repens. Specifically, we found root length to decrease locally in response to conditioned soil, and root biomass to increase in the vicinity of root litter independent of soil inoculum or litter identity. In addition, plants modified root nodulation and root diameter in response to soil biotic and litter legacy of another legume species. While many plant-soil feedback studies demonstrated poorer plant growth on soil conditioned by conspecifics compared to soil conditioned by other species (Klironomos 2002; Wubs and Bezemer 2016), no such trend was detected in this study. Instead, T. repens experienced the most negative feedback from soil biota and root litter when these were accumulated by another closely related species $V$. cracca.

\section{Soil conditioning and spatial effects}

Plants responded locally to soil conditioned by different grassland species by reducing root length in the compartment inoculated with conditioned soil relative to the root length in the compartment with control (unconditioned) soil (Fig. 1B). However, we did not detect stronger effects on plant traits from soil conditioned by conspecifics as compared to soil conditioned by heterospecifics, which is in contrast with findings of species-specific feedback effects on plant biomass shown in previous studies (Bever 1994; Kulmatiski et al. 2008; van de Voorde et al. 2011). Localised suppression of root length in soils conditioned by species monocultures independent of species identity may be due to monoculture soils accumulating more generalist pathogens than the control inoculum collected from a grassland occupied by a mixture of species. Overall, no significant decline in plant biomass was detected in response to inoculation with soil conditioned by 
different species. This finding may indicate that T. repens generally exhibits weak plant-soil feedback as has been shown for legumes in previous studies (Cortois et al. 2016). Also, T. repens could have limited the negative feedback on overall plant growth by maintaining root functioning in the control compartment with inoculum from a semi-natural grassland, despite growth reduction in the compartment with species-specific inocula (Hendriks et al. 2015b).

In contrast to some other plant trait responses, a clear localised and species-specific response to soil legacy was observed in the number of root nodules produced per unit of dry root mass, which was significantly lower in the compartment inoculated with soil conditioned by Vicia cracca (Hypotheses 1 and 2 partly supported). Rhizobium strains can form highly species-specific associations with plants (Van Berkum et al. 1995; Wang et al. 2012). It is therefore possible that $V$. cracca accumulated specific rhizobial strains that were not readily forming symbiosis with T. repens. Moreover, closely related plant species are more likely to be susceptible to the same fungal pathogens (Gilbert and Webb 2007). If closely related legumes show host-specificity in their associations with mutualists but share the same pathogens, this could result in negative feedback from heterospecific legume plants, but more neutral feedbacks from less related non-legume species as observed in this study. Moreover, pathogenic fungi can locally suppress symbiotic rhizobia (Liu et al. 2016), which could result in the reduction of nodulation in soil conditioned by closely related species. In addition, there was a tendency for a systemic response to inoculation with soil conditioned by conspecifics: $T$. repens produced lower numbers of nodules in both soil compartments when in contact with $T$. repens soil inoculum (marginally non-significant effect). Such systemic response would indicate that soil biota accumulated in the rhizosphere of conspecifics can have a negative impact on the formation of symbiosis locally as well as at the level of the whole plant through altered plant signalling.

\section{Consequences of litter effects}

Root litter addition caused a localised reduction in root biomass and nodule production independent of litter species identity. However, these responses were not significantly different from the response to an empty litterbag in the control treatment. This suggests that physical rather than chemical processes were driving the observed response. It has been shown that plants can respond to physical obstacles in the soil with the redirection of root growth into soil with fewer obstructions, as well as by reduction in root branching and specific root length in areas with high density of obstructions (McConnaughay and Bazzaz 1992; Falik et al. 2005; Semchenko et al. 2008). As plants in this study produced more root biomass but similar root length in the compartment with a litterbag (Fig. 1), it is likely that $T$. repens perceived the litterbags as obstructions and responded with the production of roots with lower specific root length. Moreover, each litterbag contained half a gram of dried root litter and this may not have been sufficient to induce significant nutrient effects. The limited effect of decomposing litter on plant foraging response may also be due to microbial immobilisation of nutrients, which may become available to plants at the later stage of decomposition (McMahon et al. 2005; Kuzyakov and Xu 2013). The plants also had limited access to mineralised nutrients due to litter being confined to a litterbag that excluded plant roots, even though mineralised nutrients could diffuse from the litterbag into the soil solution. Future studies should consider using litter mixed directly into the soil when estimating the effects of litter decomposition on plantsoil feedback (Semchenko et al. 2017).

Neither litter chemical composition nor plant functional group explained the variation in responses to root litter of different species as we found few effects of species identity (Hypothesis 3 unsupported). The only significant effect of root litter addition that was dependent on litter species identity was detected as a change in root diameter in response to $V$. cracca litter. While root diameter in the compartment with root litter remained similar to that observed in the control treatment with an empty litterbag, the roots produced in the untreated compartment were thinner compared to the control treatment with no litter in either compartment. This suggests that the local presence of $V$. cracca litter represented unfavourable conditions for $T$. repens roots and triggered a systemic response in the form of compensatory production of thinner roots in the part of the root system not directly in contact with the litter. This finding indicates that $T$. repens can distinguish specific heterogenous environmental conditions. A similar type of response to unfavourable conditions has been demonstrated in split-root systems of Trifolium subterraneum where plants distinguished between nodulating and 
non-nodulating strains of Rhizobium with respect to nodule formation (Sargent et al. 1987). While several studies used seedlings with trimmed primary roots to initiate lateral growth and create split-root plants, this study employed older plants wth more developed root systems for the same purpose. The similarity in findings between our experiment and the study above suggests that both approaches initiate localised responses in plant root systems in response to a heterogeneous environment.

\section{Conclusions}

While the legacy of plants can theoretically leave distinct effects on subsequent plant generations via litter characteristics and accumulation of specific soil biotic communities (Ke et al. 2015), there has been little focus on empirically separating the effects of plant litter and microbial soil feedback. Here we show that legacy effects mediated by soil microbiota are distinct from the effects of plant litter legacies. Moreover, heterogeneity in soil microbial legacy and litter prompted predominantly localised but also some systemic responses. These findings contribute to the growing body of studies demonstrating the ability of plants to respond locally and systemically to a diverse array of belowground cues including those related to nutrient distribution (Cahill et al. 2010), neighbours' genetic identity (Semchenko et al. 2014) and herbivore attack (Gómez et al. 2007). Besides minor changes in root biomass, we observed changes in root morphology and nodulation. Such changes in plant traits may have consequences for nutrient cycling (Prieto et al. 2016; Roumet et al. 2016) or the strength of interactions with soil mutualists. Compensatory responses to spatial heterogeneity in soil legacies may reduce the extent of negative PSF and its potential to influence species co-existence. Therefore, these results call for the refinement of current models of PSF, which are largely based on plant responses to homogeneous soil conditions and lack a spatial dimension at the level of individual root systems.

Acknowledgements The authors wish to thank Henk Martens for help in root washing and sampling and Elly Nijenhuis for sewing the litter bags. Jaap Nelemans, Gerlinde Vink and CLBB colleagues provided valuable laboratory assistance. This research was supported by NWO-ALW Vidi (grant 864.11.003) granted to GBDD, Estonian national scholarship program Kristjan Jaak granted to SS, targeted financing (IUT 20-31) provided by
Estonian Research Council and a Research Fellowship awarded to MS by the University of Manchester.

Open Access This article is distributed under the terms of the Creative Commons Attribution 4.0 International License (http:// creativecommons.org/licenses/by/4.0/), which permits unrestricted use, distribution, and reproduction in any medium, provided you give appropriate credit to the original author(s) and the source, provide a link to the Creative Commons license, and indicate if changes were made.

\section{References}

Balmer D, De Papajewski DV, Planchamp C, Glauser G, MauchMani B (2013) Induced resistance in maize is based on organspecific defence responses. Plant J 74:213-225

Bates D, Maechler M, Bolker B, Walker S (2014) lme4: linear mixed-effects models using Eigen and S4. R package version 1:1-7 http://CRAN.R-project.org/package=lme4

Baxendale C, Orwin KH, Poly F, Pommier T, Bardgett RD (2014) Are plant-soil feedback responses explained by plant traits? New Phytol 204:408-423

Van Berkum, P., Beyene, D., Vera, F.T. \& Keyser, H.H. (1995) Variability among Rhizobium strains originating from nodules of Vicia faba. Appl Environ Microbiol, 61, 2649-2653

Bever JD (1994) Feeback between Plants and Their Soil Communities in an Old Field Community. Ecology 75: $1965-1977$

Bever JD (2003) Soil community feedback and the coexistence of competitors: conceptual frameworks and empirical tests. New Phytol 157:465-473

Bezemer TM, Fountain MT, Barea JM, Christensen S, Dekker SC, Duyts H, van Hal R, Harvey JA, Hedlund K, Maraun M, Mikola J, Mladenov AG, Robin C, de Ruiter PC, Scheu S, Setälä H, Smilauer P, van der Putten WH (2010) Divergent composition but similar function of soil food webs of individual plants: plant species and community effects. Ecology 91:3027-3036

Bradford MA, Eggers T, Newington JE, Tordoff GM (2007) Soil faunal assemblage composition modifies root in-growth to plant litter patches. Pedobiologia 50:505-513

Cahill JF, McNickle GG (2011) The Behavioral Ecology of Nutrient Foraging by Plants. Annu Rev Ecol Evol Syst 42: 289-311

Cahill, J.F., McNickle, G.G., Haag, J.J., Lamb, E.G., Nyanumba, S.M. \& St Clair, C.C. (2010) Plants integrate information about nutrients and neighbors. Science (New York, N.Y.), 328, 1657

Cortois R, Schröder-Georgi T, Weigelt A, van der Putten WH, De Deyn GB (2016) Plant-soil feedbacks: role of plant functional group and plant traits. J Ecol 104:1608-1617

Dassen S, Cortois R, Martens H, de Hollander M, Kowalchuk GA, van der Putten WH, De Deyn GB (2017) Differential responses of soil bacteria, fungi, archaea and protists to plant species richness and plant functional group identity. Mol Ecol 26:4085-4098 
de Kroon H, Hutchings MJ (1995) Morphological Plasticity in Clonal Plants - the Foraging Concept Reconsidered. J Ecol 83:143-152

Ehrenfeld JG, Ravit B, Elgersma K (2005) Feedback in the PlantSoil System. Annu Rev Environ Resour 30:75-115

Eissenstat DM (1992) Costs and benefits of constructing roots of small diameter. J Plant Nutr 15:763-782

Eissenstat, D. \& Yanai, R. (1997) The Ecology of Root Lifespan. Adv Ecol Res, 27, 2-60

Falik O, Reides P, Gersani M, Novoplansky A (2005) Root navigation by self inhibition. Plant Cell Environ 28:562-569

Fitter A (1994) Architecture and biomass allocation as components of the plastic response of root systems to soil heterogeneity. In: Mcaldwell M, Pearcy RW (eds) Exploitation of environmental heterogeneity by plants. Academic Press, New York, pp 305-323

Francioli D, Schulz E, Purahong W, Buscot F, Reitz T (2016) Reinoculation elucidates mechanisms of bacterial community assembly in soil and reveals undetected microbes. Biol Fertil Soils 52:1073-1083

Garbeva P, van Veen JA, van Elsas JD (2004) Microbial diversity in soil: selection of microbial populations by plant and soil type and implications for disease suppressiveness. Annu Rev Phytopathol 42:243-270

Gilbert GS, Webb CO (2007) Phylogenetic signal in plant pathogen-host range. Proc Natl Acad Sci 104:4979-4983

Gómez S, Latzel V, Verhulst YM, Stuefer JF (2007) Costs and benefits of induced resistance in a clonal plant network. Oecologia 153:921-930

Grayston SJ, Wang S, Campbell CD, Edwards AC (1998) Selective influence of plant species on microbial diversity in the rhizosphere. Soil Biol Biochem 30:369-378

He CY, Hsiang T, Wolyn DJ (2002) Induction of systemic disease resistance and pathogen defence responses in Asparagus officinalis inoculated with nonpathogenic strains of Fusarium oxysporum. Plant Pathol 51:225-230

Hendriks, M., Mommer, L., de Caluwe, H., Smit-Tiekstra, A.E., van der Putten, W.H. \& de Kroon, H. (2013) Independent variations of plant and soil mixtures reveal soil feedback effects on plant community overyielding (ed N Wurzburger). J Ecol, 101, 287-297

Hendriks M, Ravenek JM, Smit-Tiekstra AE, van der Paauw JW, de Caluwe H, van der Putten WH, de Kroon H, Mommer L (2015a) Spatial heterogeneity of plant-soil feedback affects root interactions and interspecific competition. New Phytol: $830-840$

Hendriks M, Visser EJW, Visschers IGS, Aarts BHJ, de Caluwe H, Smit-Tiekstra AE, van der Putten WH, de Kroon H, Mommer L (2015b) Root responses of grassland species to spatial heterogeneity of plant-soil feedback. Funct Ecol 29:177-186

Hobbie SE (2015) Plant species effects on nutrient cycling: Revisiting litter feedbacks. Trends in Ecology and Evolution 30:357-363

Hodge A (2004) The plastic plant: root responses to heterogeneous supplies of nutrients. New Phytol 162:9-24

Hutchings MJ, John EA (2003) Distribution of Roots in Soil, and Root Foraging Activity. Root Ecology, 168th ed (eds H. de Kroon \& E.J.W. Visser). Springer-Verlag, Berlin, Heidelberg, pp 33-60
Ke PJ, Miki T, Ding TS (2015) The soil microbial community predicts the importance of plant traits in plant-soil feedback. New Phytol 206:329-341

Keller KR (2014) Mutualistic rhizobia reduce plant diversity and alter community composition. Oecologia 176:1101-1109

Klironomos JN (2002) Feedback with soil biota contributes to plant rarity and invasiveness in communities. Nature 417: $67-70$

Kulmatiski A, Beard KH, Stevens JR, Cobbold SM (2008) Plantsoil feedbacks: a meta-analytical review. Ecol Lett 11:980992

Kuzyakov Y, Xu X (2013) Competition between roots and microorganisms for nitrogen: Mechanisms and ecological relevance. New Phytol 198:656-669

Laguerre G, Heulin-Gotty K, Brunel B, Klonowska A, Le Quéré A, Tillard P, Prin Y, Cleyet-Marel JC, Lepetit M (2012) Local and systemic $\mathrm{N}$ signaling are involved in Medicago truncatula preference for the most efficient Sinorhizobium symbiotic partners. New Phytol 195:437-449

Lamb E, Haag J, Cahill J j (2004) Patch - background contrast and patch density have limited effects on root proliferation and plant performance in Abutilon theophrasti. Funct Ecol 18: 836-843

Liu L, Yu S, Xie ZP, Staehelin C (2016) Distance-dependent effects of pathogenic fungi on seedlings of a legume tree: impaired nodule formation and identification of antagonistic rhizosphere bacteria. J Ecol 104:1009-1019

Mack KML, Bever JD (2014) Coexistence and relative abundance in plant communities are determined by feedbacks when the scale of feedback and dispersal is local. J Ecol 102:11951201

McConnaughay K, Bazzaz F (1992) The Occupation and Fragmentation of Space: Consequences of Neighbouring Roots. Funct Ecol 12:83-98

McMahon SK, Williams M a, Bottomley PJ, Myrold DD (2005) Dynamics of Microbial Communities during Decomposition of Carbon-13 Labeled Ryegrass Fractions in Soil. Soil Sci Soc Am J 69:1238

Novozamsky I, Houba VJG, van Eck R, van Vark W (1983) A novel digestion technique for multi-element plant analysis. Commun Soil Sci Plant Anal 14:239-248

Palmer, C.M., Bush, S.M. \& Maloof, J.N. (2012) Phenotypic and Developmental Plasticity in Plants. Phenotypic and Developmental Plasticity in Plants. In: eLS. John Wiley \&Sons, Ltd: Chichester, pp. 1-9

Prieto I, Stokes A, Roumet C (2016) Root functional parameters predict fine root decomposability at the community level. J Ecol 104:725-733

van der Putten, W., Bardgett, R., Bever, J.D., Bezemer, T.M., Casper, B.B., Fukami, T., Kardol, P., Klironomos, J.N., Kulmatiski, A., Schweitzer, J.A., Suding, K., Van de Voorde, T. \& Wardle, D. (2013) Plant-soil feedbacks: the past, the present and future challenges. J Ecol, 101, 265-276

Roumet C, Birouste M, Picon-Cochard C, Ghestem M, Osman N, Vrignon-Brenas S, Cao K, Stokes A (2016) Root structurefunction relationships in 74 species: Evidence of a root economics spectrum related to carbon economy. New Phytol 210:815-826

Saar S, Semchenko M, Barel JM, De Deyn GB (2016) Legume presence reduces the decomposition rate of non-legume roots. Soil Biol Biochem 94:88-93 
Sargent L, Huang S, Rolfe B, Djordjevic M (1987) Split-root assays using Trifolium subterraneum show that Rhizobium infection induces a systemic response that can inhibit nodulation of another invasive Rhizobium. Appl Environ Microbiol 53:1611-1619

Sasaki T, Suzaki T, Soyano T, Kojima M, Sakakibara H, Kawaguchi M (2014) Shoot-derived cytokinins systemically regulate root nodulation. Nat Commun 5:4983

Schlatter DC, Bakker MG, Bradeen JM, Kinkel LL (2015) Plant community richness and microbial interactions structure bacterial communities in soil. Ecology 96:134-142

Semchenko M, Zobel K, Heinemeyer A, Hutchings MJ (2008) Foraging for space and avoidance of physical obstructions by plant roots: a comparative study of grasses from contrasting habitats. The New phytologist 179:1162-1170

Semchenko M, Saar S, Lepik A (2014) Plant root exudates mediate neighbour recognition and trigger complex behavioural changes. New Phytol 204:631-637

Semchenko M, Saar S, Lepik A (2017) Intraspecific genetic diversity modulates plant-soil feedback and nutrient cycling. New Phytol 216:90-98

Steinger T, Müller-Schärer H (1992) Physiological and growth responses of Centaurea maculosa (Asteraceae) to root herbivory under varying levels of interspecific plant competition and soil nitrogen availability. Oecologia 91:141-149 van de Voorde TFJ, van der Putten WH, Bezemer TM (2011) Intra- and interspecific plant-soil interactions, soil legacies and priority effects during old-field succession. J Ecol 99: 945-953

Van der Putten WH, Mortimer SRS, Hedlund K, Van Dijk C, Brown VK, Lepš J, Rodriguez-Barrueco C, Roy J, Diaz Len TA, Gormsen D, Korthals GW, Lavorel S, Santa Regina I, Smilauer P (2000) Plant species diversity as a driver of early succession in abandoned fields: a multi-site approach. Oecologia 124:91-99

Wang D, Yang S, Tang F, Zhu H (2012) Symbiosis specificity in the legume - rhizobial mutualism. Cell Microbiol 14:334342

Wubs ERJ, Bezemer TM (2016) Effects of spatial plant-soil feedback heterogeneity on plant performance in monocultures. $\mathrm{J}$ Ecol:364-376

Yedidia I, Benhamou N, Chet AI (1999) Induction of Defense Responses in Cucumber Plants (Cucumis sativus L.) by the Biocontrol Agent Trichoderma harzianum. Appl Environ Microbiol 65:1061-1070

Zhang H, Jennings A, Barlow PW, Forde BG (1999) Dual pathways for regulation of root branching by nitrate. Proc Natl Acad Sci 96:6529-6534

Zhang, N., Putten, W.H. Van Der \& Veen, G.F.C. (2016) Effects of root decomposition on plant - soil feedback of early- and mid-successional plant species. New Phytologist 